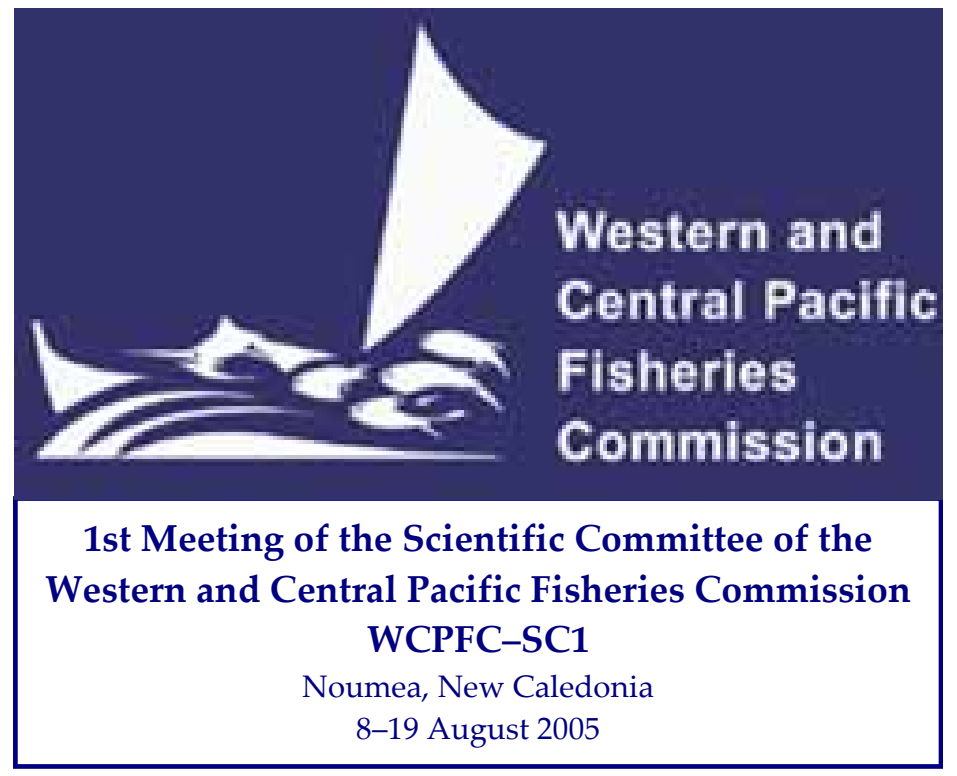

WCPFC-SC1 EB WP-7

\title{
SHIFTS IN OPEN-OCEAN FISH COMMUNITIES COINCIDING WITH THE COMMENCEMENT OF COMMERCIAL FISHING
}

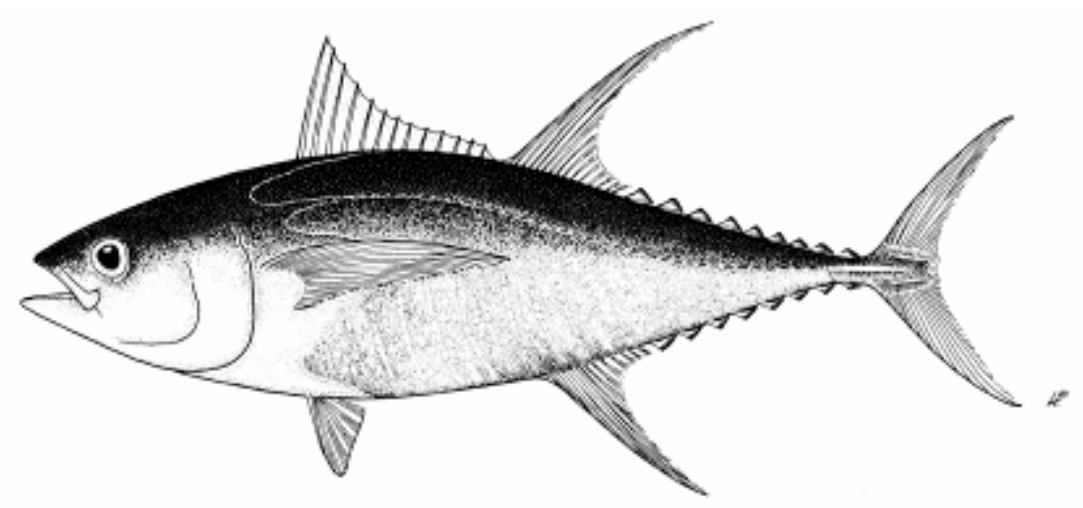

Peter Ward, Ransom A. Myers

Department of Biology, Mathematics and Statistics

Dalhousie University

Canada 


\title{
SHIFTS IN OPEN-OCEAN FISH COMMUNITIES COINCIDING WITH THE COMMENCEMENT OF COMMERCIAL FISHING
}

\author{
Peter Ward ${ }^{1}$ And Ransom A. Myers \\ Department of Biology, Dalhousie University, Halifax B3H 4J1, Canada
}

\begin{abstract}
We identify changes in the pelagic fish community of the tropical Pacific Ocean by comparing recent data collected by observers on longline fishing vessels with data from a 1950s scientific survey when industrial fishing commenced. A major shift in size composition and indices of species abundance and community biomass accompanied the start of fishing. The largest and most abundant predators, such as sharks and large tunas, suffered the greatest declines in abundance ( $21 \%$ on average). They also showed striking reductions in mean body mass. For example, the mean mass of blue shark (Prionace glauca) was $52 \mathrm{~kg}$ in the $1950 \mathrm{~s}$ compared to $22 \mathrm{~kg}$ in the $1990 \mathrm{~s}$. The estimated abundance of this species was $13 \%$ of that in the 1950s. Overall, the biomass of large predators fell by a factor of 10 between the periods. By contrast, several small and formerly rare species increased in abundance, e.g., pelagic stingray (Dasyatis violacea). However, the increases in small species did not balance the reductions in the biomass of large predators. Of three possible explanations (fishing, environmental variation, and sampling bias), available evidence indicates fishing to be the most likely cause for the observed patterns.
\end{abstract}

Key words: abundance; biomass; ecosystem stability; epipelagic zone; fishery surveys; longlining; pelagic environment; predator-prey interactions.

\section{INTRODUCTION}

There is a growing realization of the magnitude of ecosystem changes caused by the expansion of human activities into new areas and the mechanization of exploitation that began in the eighteenth century (McCann 2000). The selective removal of large animals is a characteristic of human expansion into new environments (Pauly et al. 1998, Jackson et al. 2001). Many of the large animals were apex predators with ecological roles quite different to those of other animals-by eating smaller animals they influence the diversity and abundance of lower trophic levels (Jackson and Sala 2001).

Trophic cascades occur when a reduction in predator abundance results in alternating increases and declines in lower trophic levels. Most documented cases of trophic cascades are from streams, lakes, kelp forests, and intertidal zones, or they have been created in experiments (Pace et al. 1999). Several authors (e.g., Strong 1992) assert that trophic cascades rarely occur in large, diverse ecosystems that are buffered by multiple trophic links and spatial heterogeneity.

The open ocean is a complex ecosystem. Its high species diversity, patchiness in productivity, and highly mobile and opportunistic predators should buffer against trophic cascades (Steele 1985, Angel 1993, Jen-

Manuscript received 7 November 2003; revised 6 August 2004; accepted 23 August 2004; final version received 29 September 2004. Corresponding Editor: M. A. Hixon.

${ }^{1}$ Present address: Fisheries and Marine Sciences, Bureau of Rural Sciences, GPO Box 858, Canberra ACT 2601, Australia. E-mail: peter.ward@brs.gov.au nings and Kaiser 1998, Kitchell et al. 1999). However, several features of the open ocean warrant closer scrutiny of that prediction. For example, large predators, such as tunas (Scombridae) and billfishes (Istiophoridae and Xiphiidae), must themselves survive intense predation as juveniles before reaching a size at which predation pressure diminishes. Through "cultivation effects" large predators crop down the competitors and predators of their juveniles (Walters and Kitchell 2001). Consequently, variations in predator abundance affect the survival of juveniles of those same predator species. Such feedback mechanisms and the inability of ecosystem models to accurately predict the consequences of variations in predator abundance highlight the need to monitor how natural systems actually respond to reductions in the top trophic level.

Industrial fishing represents large-scale experiments in the manipulation of trophic levels because fishing is often size-selective (Pace et al. 1999). Since the 1960s, pelagic longlines have been used throughout tropical and temperate waters of the world's oceans to catch highly migratory piscivorous tunas and billfishes. The longlines consist of a series of baited hooks attached to a mainline that is suspended from buoys floating at the sea surface. Over 50 species larger than about $5 \mathrm{~kg}$ are caught by the gear (see Plate 1). Most of the species reach that size in their first year and mature by their fourth year. Some, such as sharks and rays (Elasmobranchii), are slower growing and mature later (Last and Stevens 1994). Consequently, many species are vulnerable to the gear throughout a large part of their lives. By contrast, the prey of longline-caught fish (e.g., 

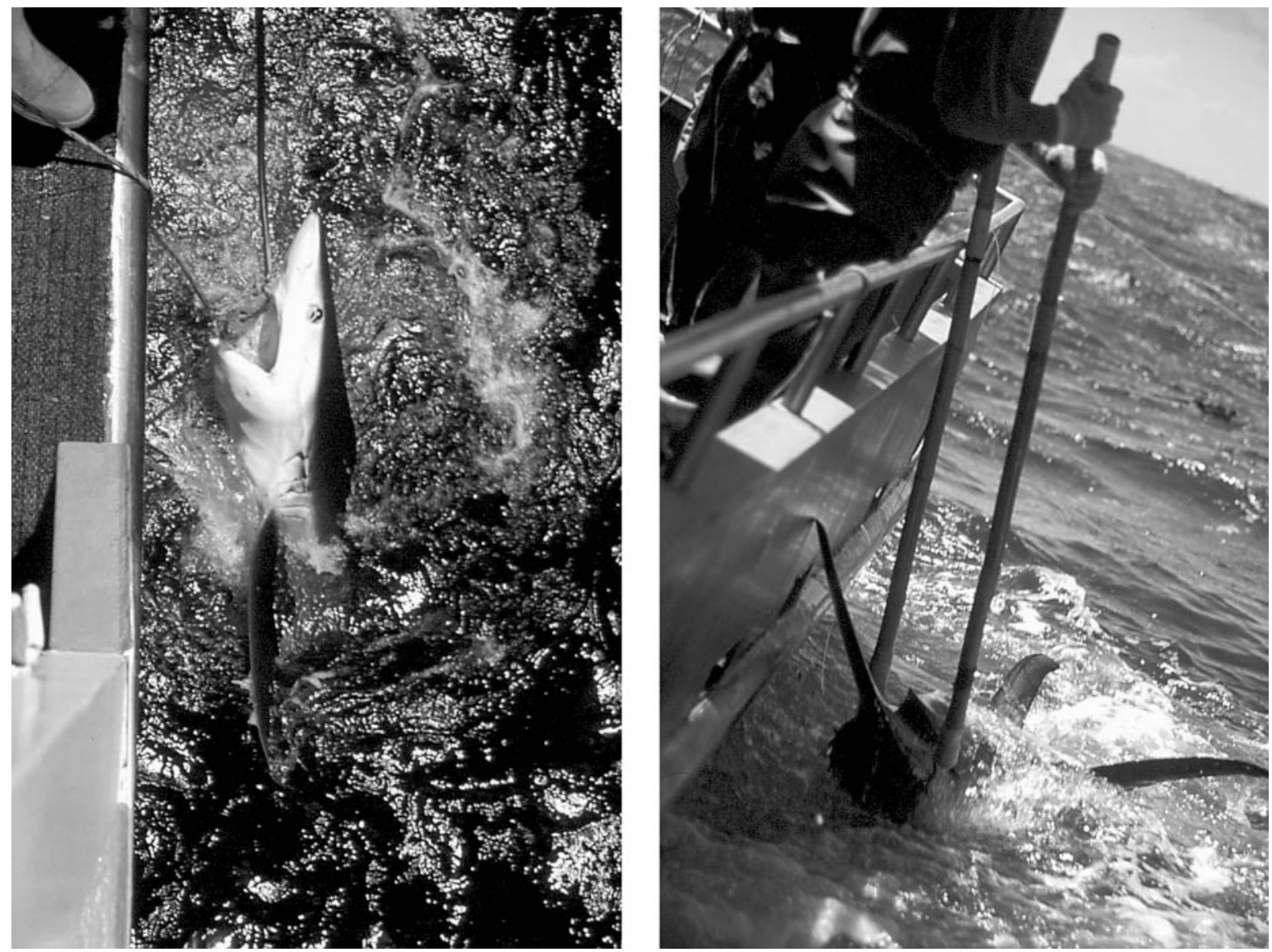

Plate 1. Blue shark (Prionace glauca; left panel) and broadbill swordfish (Xiphias gladius; right panel) caught on pelagic longlines. Photo credit: P. Ward.

squids, Cephalopoda) is rarely if ever caught by longline (Kitchell et al. 1999).

Three recent studies have examined changes in the abundance of large predators in the open ocean. Baum et al. (2003) show that several species of pelagic sharks declined by $70 \%$ during 1986-2000 in the Atlantic Ocean. Myers and Worm (2003) found a 10-fold decline in the abundance of tunas and billfishes since fishing began in the Atlantic, Pacific, and Indian Oceans. However, the analyses of Cox et al. (2002) show less pronounced declines.

The three studies analyzed data that commercial fishers reported in logbooks. Unfortunately, logbook programs often do not capture the true magnitude of community changes because they are limited to commercially valuable species, do not collect reliable body mass data, and are not implemented until well after the start of exploitation (Jackson et al. 2001). We analyze data collected by observers on commercial longliners during 1994-2002 and by a scientific survey in the early 1950 s. For both periods, the data were collected at a level of detail that allowed indices of abundance and biomass to be adjusted for variations in fishing operations, e.g., the depth of each longline hook. Our analyses quantify the abundance, biomass, and body mass of a wide range of species that constituted the pelagic fish community at the beginning of exploitation.

\section{Methods}

\section{Data}

We compare estimates of body mass and indices of abundance and biomass derived from data collected in recent years by observers on commercial longliners in the tropical Pacific with those from a scientific survey conducted in the same region in the early 1950s (Fig. 1). The U.S. National Marine Fisheries Service provided copies of the two data sets. Conducted during 1951-1958, the 1950s survey used standardized longline fishing gear and techniques. Most of the survey activities were along a survey grid during 1951-1954. Commercial longliners were chartered towards the end of the survey. Several hundred baited hooks were deployed each morning and then retrieved in the afternoon (Murphy and Shomura 1972). 


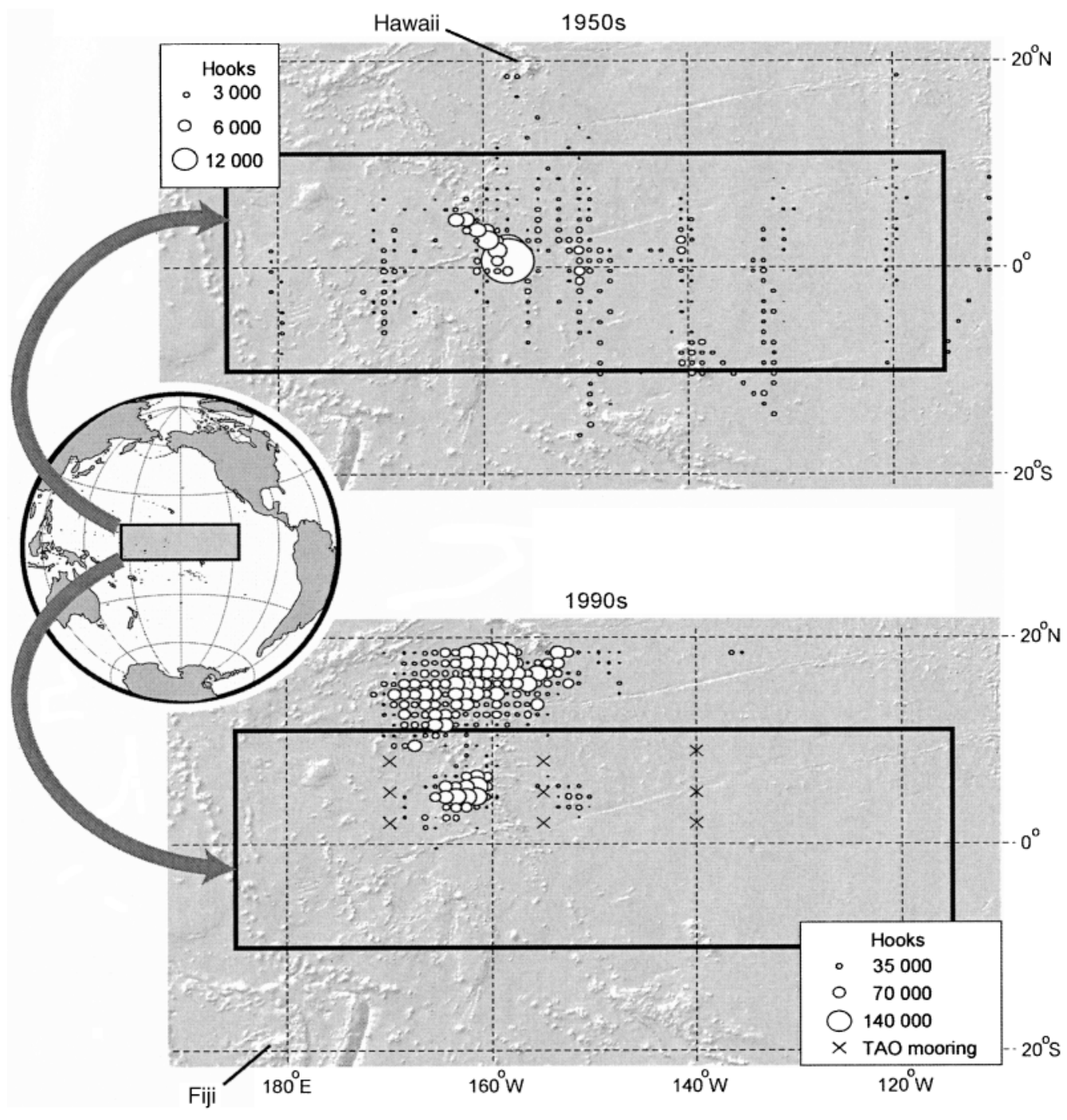

FIG. 1. Bathymetric map of the study region showing the distribution of longline fishing in each period. Circles represent the level of longline fishing effort in each one-degree square. Crosses indicate the positions of Tropical Atmosphere Ocean (TAO) moorings that we used to obtain data on thermocline depth for the 1990s. Only data gathered within the rectangle were analyzed. Catch rates for 1990s activities outside the study region in the north were at similar levels to those for $1990 \mathrm{~s}$ activities in the study region.

Observers on commercial longliners collected the recent data. Most of these activities occurred in 19992002, but for convenience are referred to as the "1990s". The data consist of 505 daily longline operations compared to 880 operations in the 1950s. The 1990s longliners targeted large tunas. They deployed more hooks (averaging 2240 hooks per day compared to 322 hooks in the 1950 s) over a wider depth range (down to $600 \mathrm{~m}$ compared to $200 \mathrm{~m}$ ) for longer periods (Fig. 2). The median soak time (the amount of time that baited hooks are available in the ocean during a daily operation) was 12 hours in the 1990s compared to 7 hours in the $1950 \mathrm{~s}$. We limited analyses to data from the two periods that provided the greatest overlap in terms of deployment time (02:00-08:00 local time) and month (January-November), within a broad region of the Pacific Ocean $\left(10^{\circ} \mathrm{S}\right.$ to $11^{\circ} \mathrm{N}, 175^{\circ} \mathrm{E}$ to $115^{\circ}$ W; Fig. 1).

The scientifically trained observers on 1990s longliners attempted to identify all species caught, as did scientists involved in the 1950s survey. However, the 1950s survey did not distinguish the various species of hammerhead sharks (Sphyrna spp.), thresher sharks (Alopias spp.), mako sharks (Isurus spp.), or snake mackerels (Gempylidae). For those species, we present indices for higher-level groups, e.g., all Alopias species together as "thresher sharks." For brevity, we use the 

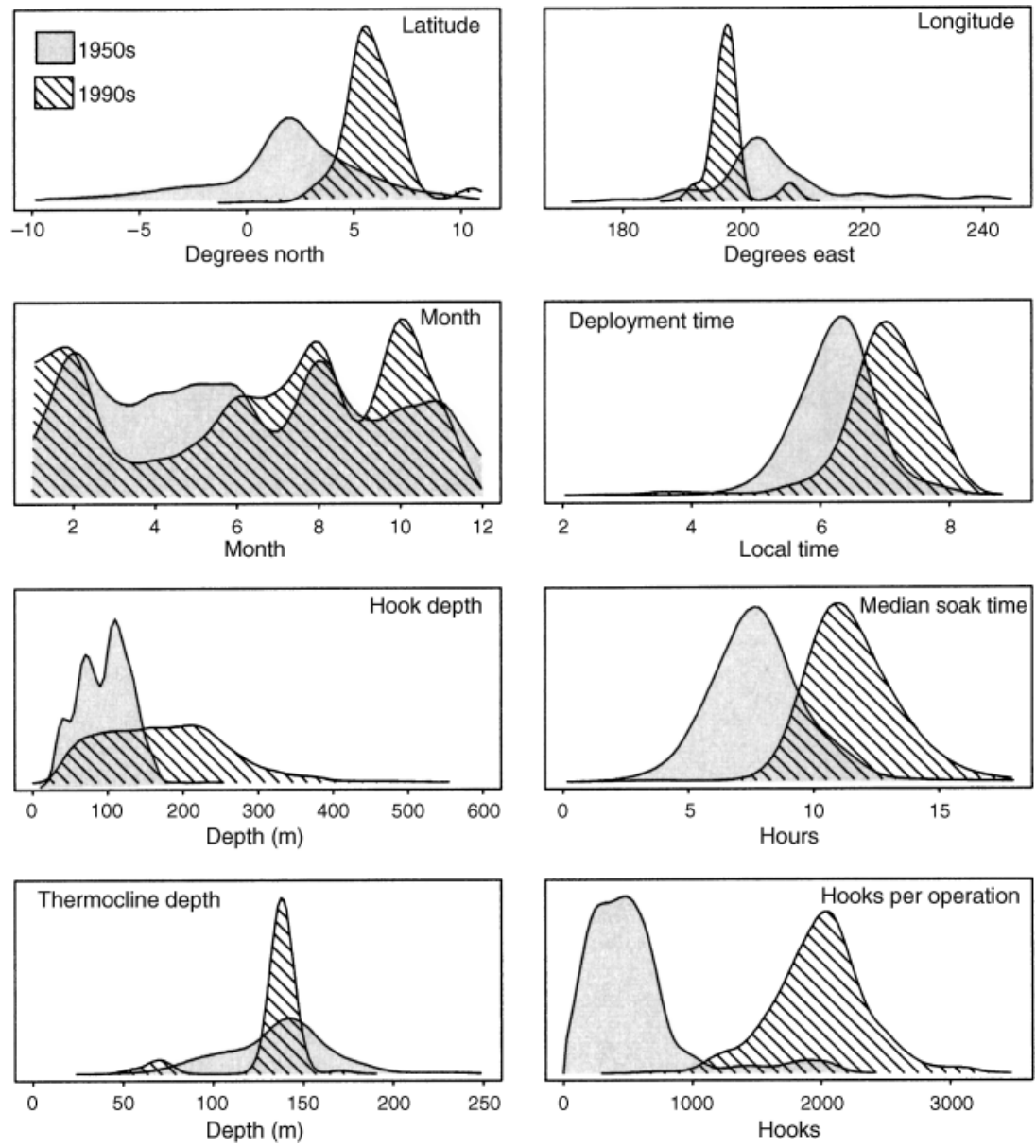

FIG. 2. Comparison of the 1950s survey (shaded) and 1990s commercial longline operations (cross-hatched) in the study region. For each period, the area of the density histogram sums to 1. Densities were smoothed with running medians. Our analyses excluded operations in December and those where the longline was deployed before 02:00 or after 08:00 local time. We derived the thermocline depth $\left(20^{\circ} \mathrm{C}\right.$ isotherm) from Tropical Atmosphere Ocean data for the 1990s (NOAA Pacific Marine Environmental Laboratory; available online). ${ }^{2}$ For the 1950 s, it was estimated from temperature profiles taken by survey longliners during 1950-1953.

term "species" to refer to species groups as well as individual species.

Much of the 1990s activity was near seamounts and islands in northwestern waters of the study region (Fig. 1), which resulted in the capture of several species that do not usually inhabit the open ocean, e.g., dusky shark (Carcharhinus obscurus). Consequently, we limited analyses to species that were not strongly associated with land masses (Appendix A).

The survey and observer data consist of daily records of gear dimensions, the number of hooks deployed, times of deployment and retrieval, the species caught, and the hook on which each fish was caught. The data enabled us to estimate the maximum depth of each hook and its soak time. Many of the fish were also measured or weighed.

${ }^{2}\langle$ www.pmel.noaa.gav/tao/ $\rangle$
To verify that commercial and survey longliners sampled similar components of the pelagic fish community, we compared 1950s catches with those of commercial longliners operating in nearby areas during 1952-1954 (Appendix A).

\section{Models for estimating abundance}

We derived indices of species abundance from generalized linear models with a negative binomial error distribution and a log link. Generalized linear models were used because they allow for nonlinear relationships between independent variables and the dependent variable (the number of a species caught), and accommodate the nonnormal distribution of the number caught. Catches were highly skewed, with many longline strata having a zero catch, a few having a catch of one, and so on. The negative binomial distribution is appropriate for overdispersed data like longline 
catches where the variance is greater than the mean (Venables and Ripley 1999).

We assumed that the number of each species caught is proportional to their abundance, after corrections are made for differences in sampling among periods and operations. We divided the data for each longline operation into 1-h soak-time strata and 40-m depth-zone strata. The probability distribution $p$ of catching $C_{i, s}$ of a given species in stratum $s$ of operation $i$ is assumed to follow a negative binomial distribution with mean catch $\mu_{i, s}$ :

$$
\begin{array}{r}
p\left(C_{i, s} ; \theta ; \mu_{i, s}\right)=\frac{\Gamma\left(\theta+C_{i, s}\right)}{\Gamma(\theta) C_{i, s} !} \frac{\mu_{i, s}^{C_{i, s}} \theta^{\theta}}{\left(\mu_{i, s}+\theta\right)^{\theta+C_{i, s}}} \\
\quad \text { for } C_{i, s}=0,1,2, \ldots
\end{array}
$$

where $\Gamma$ is the gamma function. The parameter $\theta$ is a measure of the aggregation of the data. It represents the amount of overdispersion relative to the Poisson distribution. Small values of $\theta$ indicate larger variance than that predicted by the Poisson model, i.e., $\operatorname{var}(Y)$ $=\mu+\left(\mu^{2} / \theta\right)$. As $\theta$ approaches infinity, the Poisson model is recovered, i.e., $\operatorname{var}(Y)=\mu$ (Venables and Ripley 1999).

The mean catch $\mu_{i, s}$ of a species is assumed to be the product of the fishing-effort and a combination of other variables:

$$
\begin{aligned}
\log \left(\mu_{i, s}\right)= & \beta_{0}+\beta_{1} P_{i}+\beta_{2} N_{i}+\beta_{3} N_{i}^{2}+\beta_{4} E_{i}+\beta_{5} E_{i}^{2} \\
& +\beta_{6} T_{i, s}+\beta_{7} T_{i, s}^{2}+\beta_{8} D_{i, s}+\beta_{9} D_{i, s}^{2} \\
& +\log \left(h_{i, s}\right)
\end{aligned}
$$

where $P_{i}$ is the fishing period (it is set to zero for the $1950 \mathrm{~s}$ and one for the $1990 \mathrm{~s}), N_{i}$ is the latitude, and $E_{i}$ is the longitude of longline operation $i$; and $T_{i, s}$ is the soak time, $D_{i, s}$ is the depth below the sea surface, and $h_{i, s}$ is the number of vacant hooks of each stratum $s$ of operation $i$. The $\beta_{j}$ are estimated parameters. We fitted the models separately to the data for each species. We included quadratic terms for soak time, depth, latitude, and longitude because scatter plots showed that relationships were not always linear.

The exponent of $\beta_{I}$ represents the ratio of abundance in the two periods, which we refer to as the change in abundance. We use the term "catch rate" for the number of fish actually reported per 1000 hooks, "abundance index" for the standardized catch rate expressed in terms of number of fish per 1000 hooks, and "biomass" for the abundance index multiplied by the mean mass of the species (in kilograms) in each period. The index of community biomass is the sum of biomass indices of all species.

Abundance indices are model predictions of the number of the species caught by a standard unit of longline fishing effort (1000 hooks) at a standard location, depth, and time in the study region. The models adjusted abundance indices for several factors that are known to affect the efficiency of the fishing gear (e.g., hook depth), which is otherwise assumed to be constant among operations and periods. Biomass and abundance are relative indices that do not take into account differences in vulnerability to longline gear among species. The efficiency of longline gear or "catchability" generally increases with body mass (Kleiber et al. 2003). Consequently, the true abundance of small species, such as skipjack tuna (Katsuwonus pelamis), is likely to be much greater than indicated by our abundance index.

We used three forms of Eq. 2, corresponding to the level of information available on soak time and hook depth. We used the "hook model" described in Eq. 2 for most species of tunas and sharks because estimates of the hook's soak time and depth were available for each animal caught.

We applied the "operation model" to species where the hook was not identified. It has the same form as Eq. 2, but terms are combined for each operation:

$$
\begin{aligned}
\log \left(\mu_{i}\right)= & \beta_{0}+\beta_{1} P_{i}+\beta_{2} N_{i}+\beta_{3} N_{i}^{2}+\beta_{4} E_{i}+\beta_{5} E_{i}^{2} \\
& +\beta_{6} T_{i}+\beta_{7} T_{i}^{2}+\beta_{8} B_{i}+\beta_{9} B_{i}^{2}+\log \left(h_{i}\right)
\end{aligned}
$$

where $T_{i}$ is the median soak time of operation $i$ and $B_{i}$ is the number of hooks per buoy, a commonly used index of longline depth. Preliminary analyses showed good agreement between the depth distribution predicted by the hook model and that of the operation model for most tunas and sharks. However, results for several species indicated that the operation model sometimes provided poor predictions of fish distribution at shallow depths. The third form of Eq. 2, the "offset model," replaced depth terms with a second offset:

$$
\begin{aligned}
\log \left(\mu_{i}\right)= & \beta_{0}+\beta_{1} P_{i}+\beta_{2} N_{i}+\beta_{3} N_{i}^{2}+\beta_{4} E_{i}+\beta_{5} E_{i}^{2} \\
& +\beta_{6} T_{i}+\beta_{7} T_{i}^{2}+\log \left[h_{i} \overline{f\left(D_{i}\right)}\right]
\end{aligned}
$$

where the mean depth effect $\overline{f\left(D_{i}\right)}$ is based on depth distributions derived from a wider study by P. Ward and R. A. Myers (unpublished manuscript). They inferred the depth distribution of 37 pelagic species with a generalized linear mixed effects model applied to four datasets from longline activities in the Pacific Ocean. We used their coefficients for 10 species that did not have the hook-level data required by the depth model. For each species, $\overline{f\left(D_{i}\right)}$ represents the mean effect of hook depth $D$ on relative catch rate over all hooks deployed in operation $i$ :

$\overline{f\left(D_{i}\right)}=\frac{\exp \left(\alpha+\gamma_{1} D_{i}+\gamma_{2} D_{i}^{2}+\gamma_{3} D_{i}^{3}\right)}{\exp \left(\alpha+\gamma_{1} 0.175+\gamma_{2} 0.175^{2}+\gamma_{3} 0.175^{3}\right)}$

where $\alpha$ and the $\gamma_{j}$ are parameters that Ward and Myers estimated for the species. For each operation, the offset was the mean depth effect multiplied by the number of hooks. The depth effect is standardized so that it equals one at a hook depth of $175 \mathrm{~m}$, which is the 
TABle 1. Common and scientific names of the 21 species most frequently caught in the study region of the tropical Pacific.

\begin{tabular}{|c|c|c|c|c|c|c|}
\hline \multirow[b]{2}{*}{ Common name } & \multirow[b]{2}{*}{ Scientific name } & \multirow[b]{2}{*}{ Habitat $\dagger$} & \multicolumn{2}{|c|}{ No. caught } & \multicolumn{2}{|c|}{$\begin{array}{l}\text { Mean body mass } \\
(\mathrm{kg})\end{array}$} \\
\hline & & & $1950 \mathrm{~s}$ & $1990 \mathrm{~s}$ & $1950 \mathrm{~s}$ & $1990 \mathrm{~s}$ \\
\hline \multicolumn{7}{|l|}{ Tunas and tuna-like species } \\
\hline Albacore tuna & Thunnus alalunga & I, II & 323 & 31 & 19 & 24 \\
\hline Bigeye tuna & Thunnus obesus & I, II & 694 & 2975 & 76 & 46 \\
\hline Skipjack tuna & Katsuwonus pelamis & I & 438 & 1668 & 10 & 8 \\
\hline Wahoo & Acanthocybium solandri & I & 100 & 683 & 14 & 13 \\
\hline Yellowfin tuna & Thunnus albacares & I, II & 10636 & 10625 & 52 & 28 \\
\hline \multicolumn{7}{|l|}{ Billfishes } \\
\hline Black marlin & Makaira indica & I & 38 & 2 & 134 & 35 \\
\hline Blue marlin & Makaira nigricans & I & 325 & 459 & 100 & 42 \\
\hline Sailfish & Istiophorus platypterus & I & 25 & 31 & 23 & 10 \\
\hline Shortbill spearfish & Tetrapturus angustirostris & I & 15 & 55 & 12 & 7 \\
\hline Striped marlin & Tetrapturus audax & I & 55 & 215 & 59 & 28 \\
\hline \multicolumn{7}{|l|}{ Other teleosts } \\
\hline Great barracuda & Sphyraena jello & $\mathrm{I}, \mathrm{A}$ & 19 & 97 & 14 & 7 \\
\hline Longnosed lancetfish & Alepisaurus ferox & II, I & 100 & 1699 & 3 & 3 \\
\hline Mahi mahi & Coryphaena hippurus & I & 53 & 190 & 6 & 7 \\
\hline Pomfrets & Bramidae & III, I & 0 & 637 & $\cdots$ & 3 \\
\hline Snake mackerels & Gempylidae & II, I, III & 23 & 933 & $\cdots$ & 4 \\
\hline \multicolumn{7}{|l|}{ Sharks and rays } \\
\hline Blue shark & Prionace glauca & I, II & 696 & 1081 & 52 & 22 \\
\hline Mako sharks & Isurus spp. & I & 51 & 72 & 74 & 38 \\
\hline Oceanic whitetip shark & Carcharhinus longimanus & I & 1149 & 794 & 36 & 18 \\
\hline Pelagic stingray & Dasyatis violacea & I & 0 & 302 & $\ldots$ & 3 \\
\hline Silky shark & Carcharhinus falciformis & I, II & 2210 & 1080 & 53 & 33 \\
\hline Thresher sharks & Alopias spp. & I, A, II & 112 & 511 & 17 & 12 \\
\hline
\end{tabular}

Notes: We classified species as either "small species" (1950s mean body mass less than $17 \mathrm{~kg}$, common names in lightface type) or "large predators" (bold). Classification of species that were not caught in the 1950s is based on their 1990s mean mass. Habitat categories are based on Froese and Pauly (2003) and are listed in decreasing order of importance for each species.

$\dagger$ Habitat categories: I, epipelagic zone of the open ocean (0-200 m); II, mesopelagic zone of the open ocean (200-1000 $\mathrm{m}$ ); III, benthopelagic zone of the open ocean (immediately above the sea floor); A, associated with land masses (such as seamounts, reefs, and islands).

median depth of hooks deployed by 1990s longliners. The inclusion of the depth effect scales the number of hooks in each operation, reducing the offset where the mean depth of the operation resulted in increased catchability and inflating the offset where catchability was low.

The models used only catch records where data were available for all variables, e.g., 262 of the 323 albacore tuna (Thunnus alalunga) caught in the 1950s had data on all variables used in the hook model. Consequently, we raised the abundance index of each species in each period by multiplying it by the ratio of the numbers caught and modeled.

This article focuses on the 21 species most frequently caught by longline in the study region. They represented $97.8 \%$ of the fish caught in the 1950 s and $99.7 \%$ of those caught in the 1990s. They included 19 species caught in both periods and two species that were caught only in the 1990s (pelagic stingray, Dasyatis violacea, and pomfrets, Bramidae). Body mass estimates were not available for pelagic stingray, pomfrets, or snake mackerels. For those species we used body mass estimates from a wider area of the Pacific Ocean during the 1990s (Appendix A).

\section{RESULTS}

The 19 species caught in the study region in both periods consisted of 12 species of sharks, large tunas (Thunnus spp.), and billfishes, which we refer to as "large predators," and seven "small species" with a mean body mass less than $17 \mathrm{~kg}$ (Table 1). The 1990s survey caught more species than were caught in the 1950s. The extra species caught in the 1990s all had a mean mass of less than $17 \mathrm{~kg}$.

The mean body mass of most large predators declined between the 1950s and the 1990s, whereas the mean mass of small species showed minor variations or increased (Fig. 3). The 1990s longliners deployed 1.103 million hooks and caught 24208 fish (25 fish per 1000 hooks) compared to 17439 fish caught from 0.302 million hooks in the 1950s (58 fish per 1000 hooks). Abundance indices reflected the differences in catch rates, with the indices of all large predators declining between periods (Fig. 4). Both the abundance index and mean mass of large predators declined between periods, resulting in reductions in their biomass index (Fig. 4). By contrast, biomass indices of several small species increased because their abundance index or 
mean mass increased between periods. The relationship between change in biomass and mean mass was statistically significant $(P=0.002$; Fig. 5a), as was the relationship between change in biomass and the 1950 s biomass index $(P=0.031$; Fig. $5 \mathrm{~b})$. The large predators, which dominated the pelagic fish community in the 1950s, showed the greatest declines in biomass.

Variations in body mass between the two periods tended to be more important than variations in abundance in driving changes in biomass. For all species combined, body mass reductions contributed $66 \%$ of the decline in the index of community biomass.

The index of community biomass for the 1950s was 10 times the 1990s index (Fig. 6). In terms of biomass, yellowfin tuna (Thunnus albacares) and bigeye tuna (T. obesus) were the dominant species in both periods. However, there was a reordering among the other species. Several small species rose in dominance, e.g., skipjack tuna ranked tenth in the 1950 s, then ranked third in the 1990s. The rank of several large predators, such as mako sharks, fell below that of many small species in the 1990s.

We applied the three models (Eq. 2-4) to data for each species. For simplicity, we presented the model that provided the most reliable estimate of change in abundance between the two time periods. The results from stepwise model selection were not qualitatively different from the models with all parameters estimated. Depth or hooks between floats was statistically significant for $73 \%$ of the models, followed by soak time $(62 \%)$ and latitude $(62 \%)$. Quadratic terms and longitude $(38 \%)$ were less frequently significant (Appendix B).

We investigated the robustness of abundance indices to the location of the study region's boundaries and the difference in longline depth range between periods (Appendix A). Most species showed latitudinal gradients in abundance indices, but weaker longitudinal effects. Reducing the extent of the study region down to a small area of overlap had no systematic effect on abundance indices of most species, other than increasing their confidence intervals. Consequently, we included terms for latitude and longitude in the models and used a region that had a wide geographical range. Hook depth significantly modified the estimate of change in abundance for five of the 12 species investigated. However, restricting the analyses to strata where depth was less than $200 \mathrm{~m}$ made only a small difference to the estimates.

For most tunas and billfishes, there was no statistically significant difference between catch rates reported by the 1950s survey (48 tunas and billfishes per 1000 hooks) and those of commercial longliners fishing in and adjacent to the study region in 1952-1954 (47 per 1000 hooks; Appendix A). It is noteworthy that observers on the commercial longliners during 19521954 consistently reported that external factors, such as limitations on the area of activity, kept catch rates well below levels that true commercial operations could achieve (Van Campen 1952).

\section{DiscUSSION}

Our analyses of longline data indicate significant reductions in the abundance and body mass of large predators and changes in the species composition of the pelagic fish community since the 1950s. Possible explanations of the changes include the effects of fishing, variations in oceanographic conditions, or that they are a sampling artifact. We review evidence pertinent to those hypotheses then consider how the pelagic fish community may have compensated for the changes.

\section{Hypothesis I: Differences in sampling}

We used available data and generalized linear models to standardize abundance estimates between the $1950 \mathrm{~s}$ and 1990s, e.g., longline depth. However, there were other differences in sampling between periods that we could not correct, e.g., searching for target species and gear saturation. Could our results be an artifact of those differences? Several independent lines of evidence show that this is unlikely and, if anything, we have underestimated the decline in large predators.

The density of hooks in the 1990s (40 m between hooks) was about $80 \%$ that in the 1950 s $(50 \mathrm{~m})$. It is not known how increased hook density might affect catch rates. Neither did we investigate the possibility that the increased number of vessels fishing for pelagic species in the study region after the 1950s increased competition for the most productive areas. Such competition may result in the displacement of some longliners to less productive waters.

There is firmer evidence that differences in sampling resulted in the underestimation of the extent of the decline in abundance. First, the 1990s longliners actively searched for target species, whereas the 1950s data were mostly from a predetermined survey grid. Abundance is overestimated in the 1990s because longliners concentrated on areas where fish-finding equipment (e.g., sea-surface temperature imagery), recent catches, and past experience indicated that fishing would yield the highest financial returns. Operating costs, such as distance from port, were a consideration. However, the expected catch of bigeye tuna and yellowfin tuna was the main factor determining the location of 1990s activities within the study region (T. Swenarton, personal communication).

Second, the concentration of 1990s activity near seamounts and islands resulted in elevated catch rates for many species. Several studies have shown that proximity to land masses influences the local abundance of pelagic fish species, e.g., Murphy and Shomura (1972). Our models adjusted abundance indices for latitude and longitude, but did not include a specific term for distance from land.

Third, detailed descriptions of the fishing and sampling show many similarities between the periods, e.g., 
a) Large predators
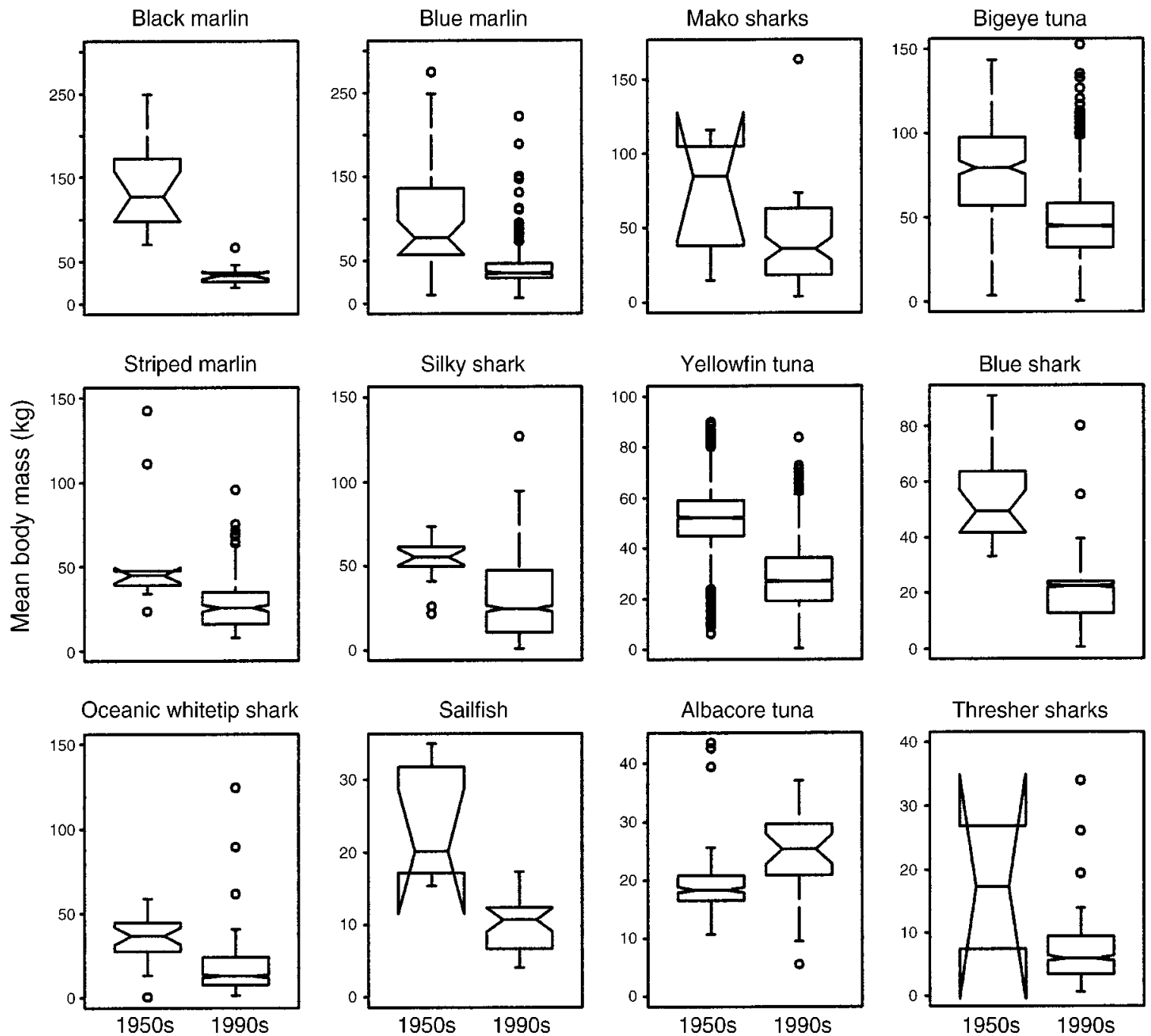

FIG. 3. Variations in the body mass of 18 species between periods. In this article, we present indices for the 21 most frequently caught species, but body mass estimates were not available for three of those species in the 1950s, and they are not shown in Figs. 3a, b, or 5a. Species are in descending order of their 1950s mean mass. The scientists involved in the 1950s weighed fish, whereas we predicted mass from length-mass relationships applied to length measurements reported by observers in the 1990s. The box plots show the interquartile range (IQR), which is the difference between the first and third quartiles, thus containing $50 \%$ of observations. Box plots are sometimes inside-out where the sample size is small and the confidence interval (CI) is wider than the interquartile range.

similar hook sizes, wire leaders, sardines as bait, and the time of longline deployment. However, the 1990s longliners connected hooks to mainlines with monofilament-nylon branchlines. They produce higher catch rates than the rope branchlines used in the 1950s (Stone and Dixon 2001). We were unable to adjust indices for these improvements in fishing gear, the effects of fishing near seamounts and islands, or for searching and experience. However, those differences would have resulted in 1990s abundance being overestimated rather than underestimated.

\section{Hypothesis II: Variations in oceanographic conditions}

There is no doubt that changes in oceanographic conditions affect the recruitment of marine fishes (Myers 1998, Ravier and Fromentin 2004), variations in productivity (Mantua and Hare 2002, Chavez et al. 2003), and the efficiency of longline gear (Bigelow et al. 2002). Oceanographic conditions certainly caused some of the variation in abundance seen in our study. Moreover, the effects of oceanographic conditions are difficult to dismiss because they may involve time-lags, 
b) Small species

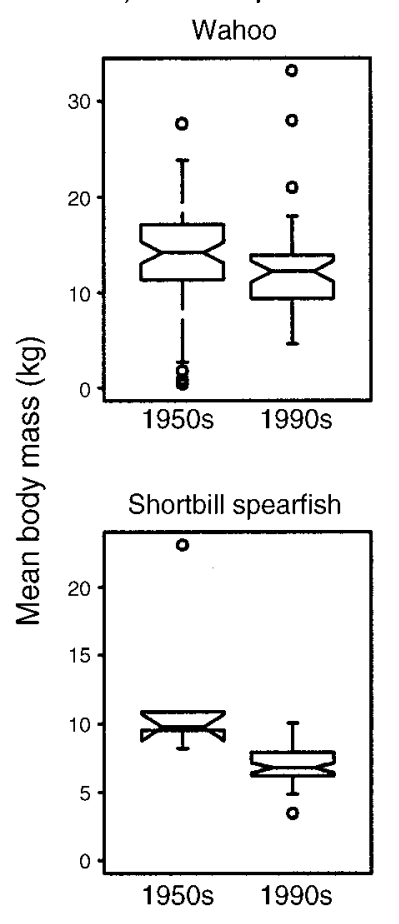

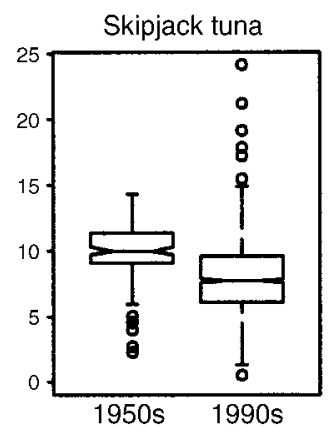

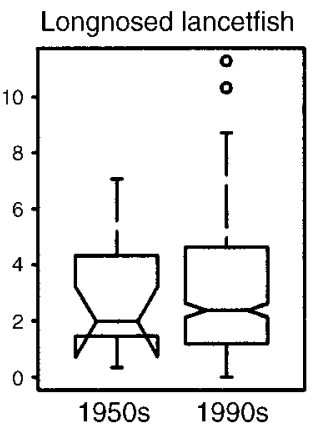

FIG. 3.
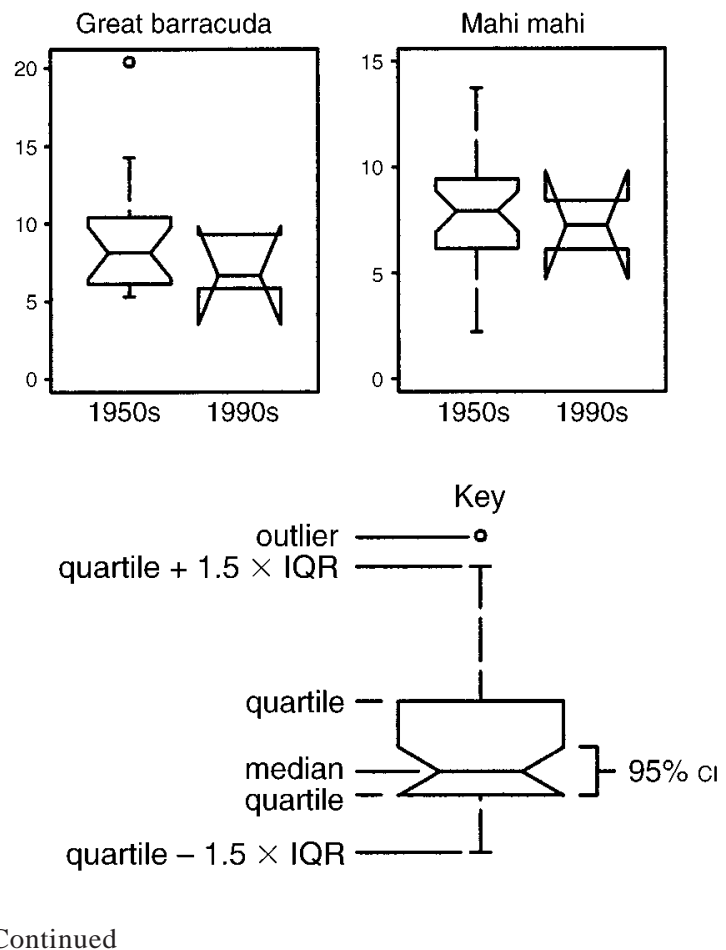

and they may range from long-term effects like regime shifts to short-term effects. However, there are two reasons to believe that they were not the major cause of the changes observed in the pelagic fish community of the tropical Pacific.

First, there was no obvious difference between periods in several oceanographic indices that are often associated with variations in productivity and fish distribution (Appendix A). Second, there is no reason to believe that changes in oceanographic conditions would exactly mimic the changes predicted by fishing. The oceanographic hypothesis must demonstrate a mechanism that explains a pattern where the body mass and abundance of large predators declined while small species increased in abundance. Those changes occurred among 12 species of large predators and nine small species that have diverse life histories. The large predators, for example, range from fast-growing yellowfin tuna that mature at two years of age, through to mako sharks that mature at eight years or older and may live for decades (Froese and Pauly 2003). The pattern of changes in community composition, body mass, and abundance are not consistent with any known oceanographic changes.

Nevertheless, it is difficult to assess hypotheses without a time-series of indices. Repeating the 1950s survey would provide an empirical test of hypotheses I and II. Such a survey would need to cover similar oceanographic conditions and replicate the 1950s sampling design, fishing gear, and techniques. In many other fish- eries, regular surveys are used to gather information for assessments because of problems in standardizing commercial logbook data, e.g., searching and variations in fishing gear.

\section{Hypothesis III: Ecosystem effects of fishing}

Fishing has been extensively documented as a cause of fish population declines. It affects populations directly through removals or indirectly by modifying the ecosystem's trophic structure or habitats (Jennings and Kaiser 1998). Longliners have removed millions of large predators from the study region each year, with many more tunas removed by other fishing gears, such as purse-seine. Furthermore, the 1950s fish community was not pristine. Pelagic fish species, such as albacore tuna and yellowfin tuna, had been commercially harvested in the Pacific Ocean since the early 1900s (Nakamura 1950).

Nevertheless, there are several inconsistencies between our results and those of other assessments. Cox et al. (2002) found smaller changes in large predators than we observed. They used an ecosystem model to investigate changes in populations of tunas and billfishes in a much wider area of the Pacific Ocean. Our results also contradict accepted age-based stock assessments for commercially important tuna and billfish species. The substantial decline in abundance indicated by our analyses suggests that the original populations were relatively small. However, the populations subsequently supported much higher catch levels since the 


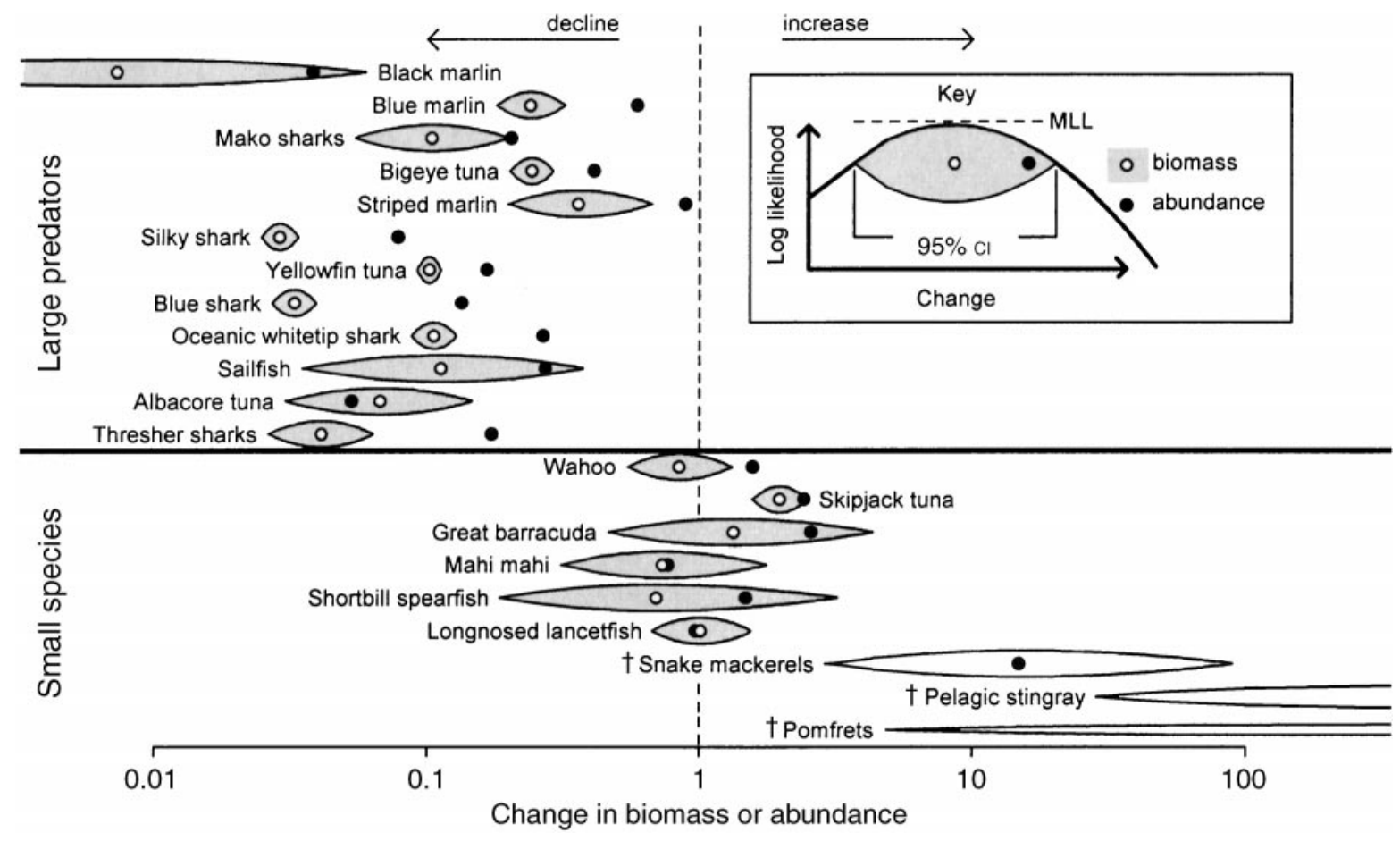

FIG. 4. Change in indices of biomass (open circles) and abundance (solid circles) between periods. The 21 species are shown in descending order of their mean body mass. A value of 1.0 indicates no change in the biomass (or abundance) index, a value of 0.1 indicates a 10 -fold decline, and a value of 10 indicates a 10 -fold increase. The shaded regions are "raindrop plots" (Barrowman and Myers 2003) representing approximate 95\% confidence intervals (CI) of the change in biomass obtained from profile likelihoods. The maximum log likelihood (MLL) estimate of biomass change is shown at the vertical center of the raindrop. Indices could not be estimated for pelagic stingray or pomfrets because they were not caught in the 1950s. However, the lower limits of their confidence intervals for abundance could be estimated and are shown. Species marked with $\dagger$ are ones in which the confidence intervals represent the change in abundance because no body mass data were available for that species in the $1950 \mathrm{~s}$.

1950s, indicating that they may have been much larger than indicated by our estimates.

However, those analyses did not include sharks, the group that showed the largest declines in our study. Also contributing to the inconsistencies are the nonlinear relationship between commercial catch rates and abundance, particularly for purse-seine catch rates, and the fact that the populations were already exploited by the start of their study period. Our analyses require fewer assumptions than age-structured assessments and ecosystem models. Our findings are consistent with those of Myers and Worm (2003) and the strong, sizedependent patterns predicted by many models of the effects of fishing (Myers and Mertz 1998b). The changes in body mass are typical of a demographic change known as the "fishing down of an accumulated biomass" (Hilborn and Walters 1987). The initial reduction in biomass by size-selective fishing takes the form of a disproportionate reduction in large animals that had few natural enemies. Increased fishing mortality since the 1950s has prevented large predators, particularly sharks, from reaching a large mass because of their low growth rates combined with the time required to reach that size.
Although our study is limited to two snapshots of the community, the similarity of the changes to declines in large sharks reported in the northwestern Atlantic (Baum et al. 2003), Gulf of Mexico (Baum and Myers 2004), and global declines in commercial catch rates (Myers and Worm 2003) indicate that it is linked to fishing.

\section{Compensatory responses}

Our analyses did not reveal any clear evidence of species extirpation, but several species that were caught in the 1990s were not reported in the 1950s. The additional species included: (1) mesopelagic and benthopelagic species caught by the deep longlines used in the 1990s (e.g., escolar, Lepidocybium flavobrunneum); (2) species caught by 1990 s longliners fishing near land masses (e.g., dusky shark); (3) rare species that were probably an artifact of the larger sample size in the 1990s (e.g., Pacific bluefin tuna, Thunnus orientalis); and (4) extra species that were caught in large numbers, are not associated with deep longlining or land masses, and are easily distinguished from other species. The extra species included pelagic stingray, slender sunfish (Ranzania laevis), and pomfrets. We contacted a former 

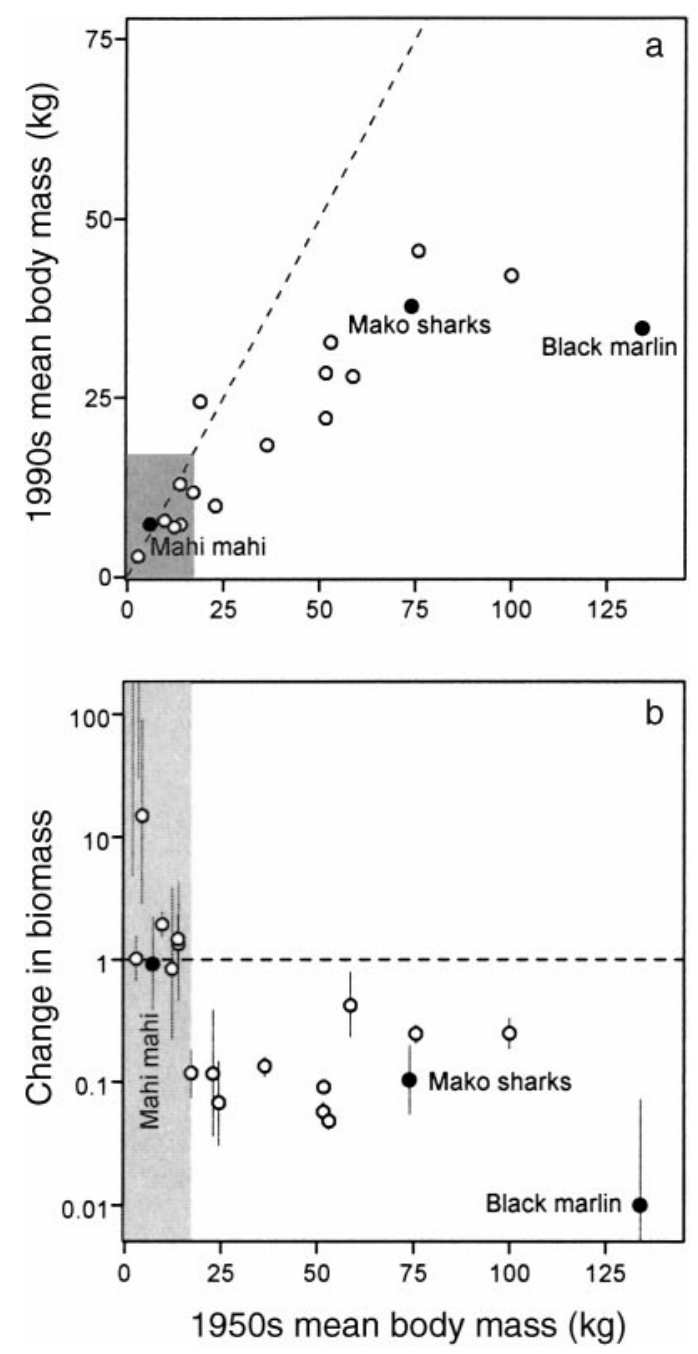

FIG. 5. Body mass relationships. Several species are labeled and have solid symbols to assist comparison between panels. Background shading indicates small species $(<17 \mathrm{~kg})$. (a) The mean mass of each species in the 1990s plotted against its 1950 s mean mass. Pomfrets, pelagic stingray, and snake mackerels are not plotted because estimates of their mean masses were not available for the 1950s. The dashed line is the line of equality between mean mass in the two periods. (b) The relationship between the change in biomass for 21 species and 1950s mean mass (or 1990s mean mass for the three species that did not have body mass data in the 1950s). The vertical bars are approximate $95 \%$ confidence intervals for the change in biomass. Only the lower limits of the confidence intervals for change in abundance of pomfrets and pelagic stingray are shown at the top left-hand corner of panel (b).

survey scientist, R. Shomura (personal communication), who confirmed that the 1950 s survey did not encounter the extra species in the study region.

Increases in the biomass indices of several small species and the appearance of extra species are consistent with release from predation. Pomfrets, for example, may have increased because of the reduction in the abundance of their predators, which include large tunas (Collette and Nauen 1983), billfishes (Nakamura 1985), and sharks (Last and Stevens 1994). Most small species would have a very low catchability due to their small gape. Skipjack tuna, for example, are not caught by longline until they are mature, affording some protection from overexploitation by the gear (Myers and Mertz 1998a, Hampton 2000). They increased despite a substantial expansion in their harvesting by purseseine fishing gear in the tropical Pacific (Cox et al. 2002). Pelagic stingray were caught in considerable numbers in the $1990 \mathrm{~s}$, but are unlikely to have been an artifact of deep longlining or activities near land masses because they inhabit the epipelagic zone of the open ocean (Mollet 2002). It is also noteworthy that pelagic stingray were not marketed. They are often alive when longlines are retrieved, and they might survive when released alive.

Expansion in the distribution of prey in response to reductions in the abundance of their predators is another possible explanation of the increased abundance of small species observed in the study region. Many studies have reported changes in the microhabitat utilization of prey species following the introduction or removal of predators, e.g., Werner et al. (1983). A change in depth distribution may have contributed to the increases in abundance that we estimated for small species. The removal of large predators would allow small species to move into habitats (e.g., epipelagic waters during the day) that were originally the domain of large predators.

\section{Contraction of biomass}

The index of the biomass of pelagic fish available to longline gear in the 1990 s was less than $10.3 \%$ of

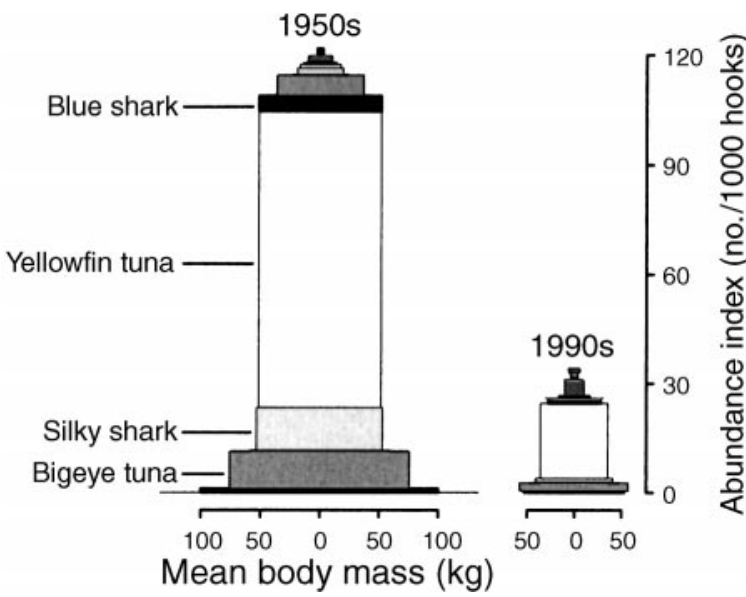

FIG. 6. Change in biomass of the pelagic fish community. Each bar represents one species (species associated with land masses are excluded). The height of each bar is scaled to the abundance index, and its width is scaled to mean body mass so that the bar's area represents biomass (mass [kg] per 1000 hooks). The four most abundant species in the 1950s are labeled. The shading and the order in which each species is shown are the same for both periods. 
that in the 1950s. The large predators were $9.7 \%$ of their 1950s biomass index, which agrees with the $88.5 \%$ decline in the abundance of tunas and billfishes estimated by Myers and Worm (2003) for all oceans.

The amount of energy entering an ecosystem through primary production balances the energy lost through waste products, decay, respiration, and other activities (Valiela 1995). A small portion of the energy that once supported populations of large predators is now removed as commercial catches. The balance must be consumed by other pelagic species or it might sink to abyssal depths to be utilized by other animals and detritivores or eventually become buried in sediments. Our analyses revealed relatively minor increases in the biomass of small pelagic species (e.g., pelagic stingray), which may represent release from predation. We would also expect the competitive release of species at the same trophic level as large predators, e.g., false killer whale (Pseudorca crassidens). Alternative sources of information must be investigated to determine how other components of the ecosystem have compensated for the reduction in larger predators because their competitors and prey are rarely, if ever, caught by longline fishing gear.

\section{Implications of reductions}

The changes in the pelagic fish community might not have reduced the harvest levels that the system can sustain. A fish community consisting of many small fish will sustain higher exploitation rates than a community dominated by large, old fish (Myers and Mertz 1998a).

Beyond the economic considerations of the community changes are implications for the functioning of the ecosystem and biodiversity. The substantial reduction in the biomass of large pelagic predators since the 1950 s follows the global pattern of reduction in mean trophic level identified by Pauly et al. (1998). Ecosystem models (e.g., Steele and Schumacher 2000, Cox et al. 2002) can predict many community changes. The addition of early survey data, like that analyzed in the present paper, will help those models to predict the magnitude of changes caused by the selective reduction of large predators. However, we have no experience with how those changes may have affected the overall stability and persistence of the system. Neither is it clear whether the pelagic fish community has stabilized or whether reductions in predator abundance, community biomass, and body mass are continuing.

\section{CONCLUSIONS}

Our analyses show that only a remnant of the original fish community remains in a large region of the tropical Pacific. The index of community biomass is about $10 \%$ of its former level and the community is composed of smaller fish and fewer large predators. The changes are typical of a large and fundamental reordering of the pelagic ecosystem of the world's open oceans. The ad- vent of industrial longline fishing coincided with these changes. The 1950s longlining survey could be repeated to determine the exact extent of the community changes and whether they were due to variations in oceanographic conditions or sampling. The implications of the changes in open-ocean fish communities on ecosystem stability and persistence are highly uncertain.

\section{ACKNOWLEDGMENTS}

The Pelagic Fisheries Research Program (PFRP), Future of Marine Animal Population Project of the Census of Marine Life, NSERC, and the Killam Foundation supported this work. This research is part of a larger project initiated and supported by the Pew Charitable Trusts. The views expressed in this article are those of the authors and do not necessarily reflect the views of funding bodies. Kurt Kawamoto, Naozumi Miyabe, Brent Miyamoto, Ziro Suzuki, Tom Swenarton, and Peter Williams provided data and information on the fisheries. Julia Baum, Wade Blanchard, Justin Breen, Albert Caton, Ian Jonsen, Dan Kehler, Ramzi Mirshak, Aswea Porter, Richard Shomura, Wilvan Van Campen, Boris Worm, and two reviewers provided technical advice and comments on the manuscript.

\section{Literature Cited}

Angel, M. V. 1993. Biodiversity of the pelagic ocean. Conservation Biology 7:760-772.

Barrowman, N. J., and R. A. Myers. 2003. Raindrop plots: a new way to display collections of likelihoods and distributions. American Statistician 57:268-274.

Baum, J. K., and R. A. Myers. 2004. Shifting baselines and the decline of pelagic sharks in the Gulf of Mexico. Ecology Letters 7:135-145.

Baum, J. K., R. A. Myers, D. G. Kehler, B. Worm, S. J. Harley, and P. A. Doherty. 2003. Collapse and conservation of shark populations in the northwest Atlantic. Science 299: 389-392.

Bigelow, K. A., J. Hampton, and N. Miyabe. 2002. Application of a habitat-based model to estimate effective longline fishing effort and relative abundance of Pacific bigeye tuna (Thunnus obesus). Fisheries Oceanography 11:143155.

Chavez, F. P., J. Ryan, S. Lluch-Cota, and M. Niquen. 2003. From anchovies to sardines and back: multidecadel change in the Pacific Ocean. Science 299:217-221.

Collette, B. B., and C. E. Nauen. 1983. Scombrids of the world. An annotated and illustrated catalogue of tunas, mackerels, bonitos and related species known to date. United Nations Development Programme, Food and Agriculture Organization of the United Nations, Rome, Italy.

Cox, S. P., S. J. D. Martell, C. J. Walters, T. E. Essington, J. F. Kitchell, C. Boggs, and I. Kaplan. 2002. Reconstructing ecosystem dynamics in the central Pacific Ocean, 19521998. I. Estimating population biomass and recruitment of tunas and billfishes. II. A preliminary assessment of the trophic impacts of fishing and effects on tuna dynamics. Canadian Journal of Fisheries and Aquatic Sciences 59: 1724-1747.

Froese, R., and D. Pauly. 2004. FishBase. WorldFish Center. $\langle$ www.fishbase.org $\rangle$.

Hampton, J. 2000. Natural mortality rates in tropical tunas: size really does matter. Canadian Journal of Fisheries and Aquatic Sciences 57:1002-1010.

Hilborn, R., and C. J. Walters. 1987. A general model for simulation of stock and fleet dynamics in spatially heterogeneous fisheries. Canadian Journal of Fisheries and Aquatic Sciences 44:1366-1375. 
Jackson, J. B. C., et al. 2001. Historical overfishing and the recent collapse of coastal ecosystems. Science 293:629638.

Jackson, J. B. C., and E. Sala. 2001. Unnatural oceans. Scientia Marina 65:273-281.

Jennings, S., and M. J. Kaiser. 1998. The effects of fishing on marine ecosystems. Advances in Marine Biology 34: 201-352.

Kitchell, J. F., C. Boggs, P. He, and C. J. Walters. 1999. Keystone predators in the central Pacific. Pages 665-684 in J. N. Ianelli, editor. Ecosystem approaches for fisheries management. University of Alaska Sea Grant, Fairbanks, Alaska, USA.

Kleiber, P., M. G. Hinton, and Y. Uozumi. 2003. Stock assessment of blue marlin (Makaira nigricans) in the Pacific Ocean using Multifan-CL. Marine and Freshwater Research 54:348-360.

Last, P. R., and J. D. Stevens. 1994. Sharks and rays of Australia. CSIRO Australia, Hobart, Australia.

Mantua, N. J., and S. R. Hare. 2002. The Pacific decadal oscillation. Journal of Oceanography 58:35-44.

McCann, K. 2000. The diversity-stability debate. Nature 405: 228-233.

Mollet, H. F. 2002. Distribution of the pelagic stingray, Dasyatis violacea (Bonaparte, 1832), off California, Central America, and worldwide. Marine and Freshwater Research 53:525-530.

Murphy, G. I., and R. S. Shomura. 1972. Pre-exploitation abundance of tunas in the equatorial central Pacific. Fishery Bulletin 70:875-913.

Myers, R. A. 1998. When do environment-recruit correlations work? Reviews in Fish Biology and Fisheries 8:285305.

Myers, R. A., and G. Mertz. 1998a. The limits to exploitation: a precautionary approach. Ecological Applications 8:S165S169.

Myers, R. A., and G. Mertz. 1998b. Reducing uncertainty in the biological basis of fisheries management by meta-analysis of data from many populations: a synthesis. Fisheries Research Amsterdam 37:51-60.

Myers, R. A., and B. Worm. 2003. Rapid worldwide depletion of predatory fish communities. Nature 423:281-283.

Nakamura, H. 1950. The Japanese long-line fishery for tunas. U.S. Fish and Wildlife Service. Commercial Fisheries Review 12:1-26.
Nakamura, I. 1985. FAO species catalogue. Volume 5. Billfishes of the world. An annotated and illustrated catalogue of marlins, sailfishes, spearfishes and swordfishes known to date. United Nations Development Programme, Food and Agriculture Organization of the United Nations, Rome, Italy.

Pace, M. L., J. J. Cole, S. R. Carpenter, and J. F. Kitchell. 1999. Trophic cascades revealed in diverse ecosystems. Trends in Ecology and Evolution 14:483-488.

Pauly, D., V. Christensen, J. Dalsgaard, R. Froese, and F. Torres. 1998. Fishing down marine food webs. Science 279:860-863.

Ravier, C., and J.-M. Fromentin. 2004. Are the long-term fluctuations in Atlantic bluefin tuna (Thunnus thynnus) population related to environmental changes? Fisheries Oceanography 13:145-160.

Steele, J. H. 1985. A comparison of terrestrial and marine ecosystems. Nature 313:355-358.

Steele, J. H., and M. Schumacher. 2000. Ecosystem structure before fishing. Fisheries Research 44:201-205.

Stone, H. H., and L. K. Dixon. 2001. A comparison of catches of swordfish, Xiphias gladius, and other pelagic species from Canadian longline gear with alternating monofilament and multifilament nylon gangions. Fishery Bulletin 99: $210-216$

Strong, D. R. 1992. Are trophic cascades all wet? Differentiation and donor-control in speciose ecosystems. Ecology 73:747-754.

Valiela, I. 1995. Marine ecological processes. Second edition. Springer-Verlag, New York, New York, USA.

Van Campen, W. G. 1952. Japanese mothership-type tuna fishing operations in the western equatorial Pacific, JuneOctober 1951 (Report of the seventh, eighth and ninth expeditions). U.S. Fish and Wildlife Service. Commercial Fisheries Review 14:1-9.

Venables, W. N., and B. D. Ripley. 1999. Modern applied statistics with S-Plus. Third edition. Springer-Verlag, New York, New York, USA.

Walters, C., and J. F. Kitchell. 2001. Cultivation/depensation effects on juvenile survival and recruitment: implications for the theory of fishing. Canadian Journal of Fisheries and Aquatic Sciences 58:39-50.

Werner, E. E., J. F. Gilliam, D. J. Hall, and G. G. Mittelbach. 1983. An experimental test of the effects of predation risk on habitat use in fish. Ecology 64:1540-1548.

\section{APPENDIX A}

A description of the estimation of relative abundance and biomass using longline data from surveys and observers is presented in ESA's Electronic Data Archive: Ecological Archives E086-043-A1.

\section{APPENDIX B}

An explanation of parameter estimates and diagnostic statistics for generalized linear models used to estimate relative abundance is presented in ESA's Electronic Data Archive: Ecological Archives E086-043-A2. 